\title{
Erratum to: Effect of the different shapes of silver particles in conductive ink on electrical performance and microstructure of the conductive tracks
}

\author{
Xiaojian Yang $\cdot$ Wei He $\cdot$ Shouxu Wang $\cdot$ \\ Guoyun Zhou $\cdot$ Yao Tang $\cdot$ Juanhong Yang
}

Published online: 28 July 2012

(C) Springer Science+Business Media, LLC 2012

Erratum to: J Mater Sci: Mater Electron (2012)

DOI 10.1007/s10854-012-0691-z

In the original publication of the article, there are some errors in Fig. 7. The correct version of Fig. 7 is provided below where the original text remains the same.

Fig. 7 a The inkjet-printed patterns using a mixture of silver nanorods and nanoparticles on the glass substrate, $\mathbf{b}$ the printed dot, and c the printed line
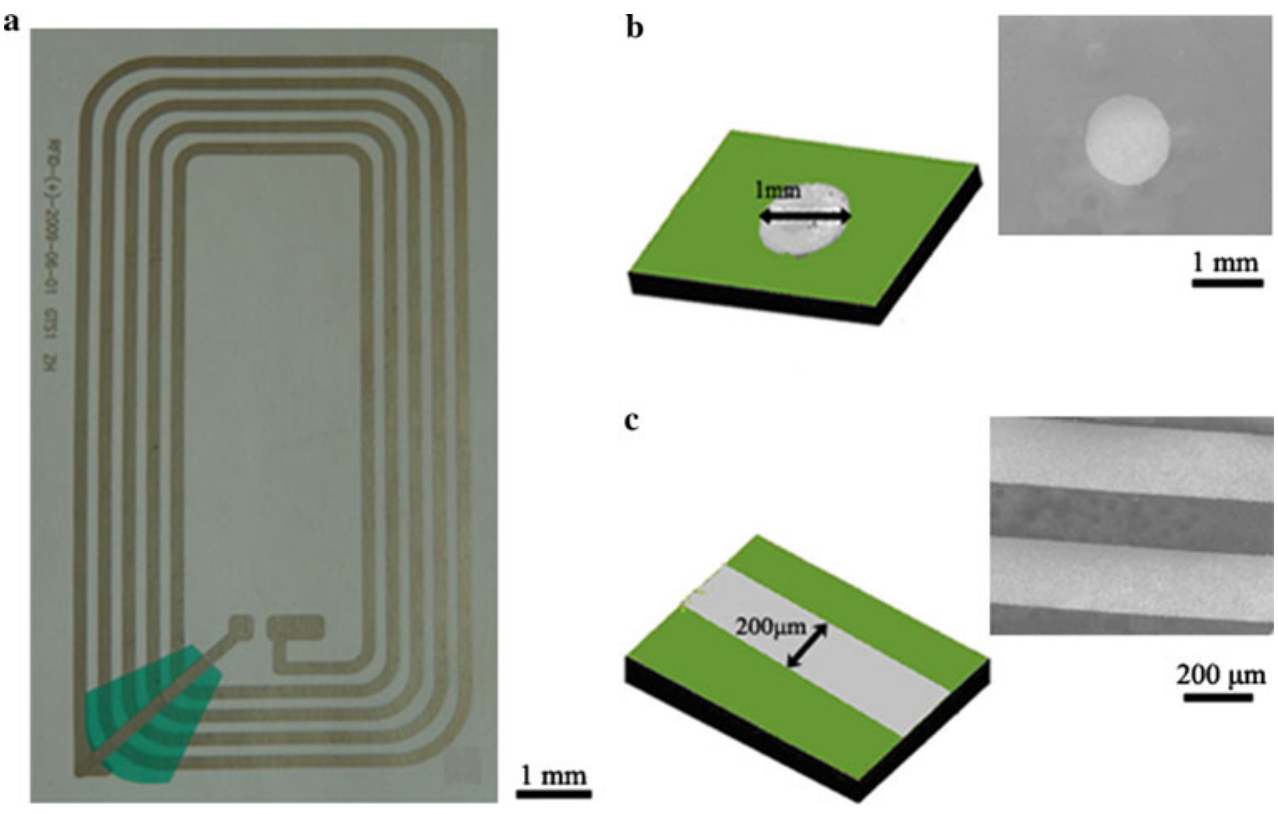

The online version of the original article can be found under doi:10.1007/s10854-012-0691-z.

X. Yang $(\bowtie) \cdot$ W. He $\cdot$ S. Wang $\cdot$ G. Zhou $\cdot$ Y. Tang $\cdot$ J. Yang State Key Laboratory of Electronic Thin Films and Integrated Devices, University of Electronic Science and Technology of China, Chengdu 610054, Sichuan, People's Republic of China e-mail: yangxiaojian986@126.com 